\title{
Beyond the classroom: The need for support for parents with a child diagnosed with autism, ID, and behavioral problems
}

\author{
Erica Curington
}

Follow this and additional works at: https://researchrepository.wvu.edu/etd

\section{Recommended Citation}

Curington, Erica, "Beyond the classroom: The need for support for parents with a child diagnosed with autism, ID, and behavioral problems" (2017). Graduate Theses, Dissertations, and Problem Reports. 5420. https://researchrepository.wvu.edu/etd/5420

This Dissertation is protected by copyright and/or related rights. It has been brought to you by the The Research Repository @ WVU with permission from the rights-holder(s). You are free to use this Dissertation in any way that is permitted by the copyright and related rights legislation that applies to your use. For other uses you must obtain permission from the rights-holder(s) directly, unless additional rights are indicated by a Creative Commons license in the record and/ or on the work itself. This Dissertation has been accepted for inclusion in WVU Graduate Theses, Dissertations, and Problem Reports collection by an authorized administrator of The Research Repository @ WVU.

For more information, please contact researchrepository@mail.wvu.edu. 
Beyond the classroom: The need for support for parents with a child diagnosed with autism, ID, and behavioral problems

\title{
Erica Curington
}

\author{
Dissertation submitted \\ to the College of Education and Human Services \\ at West Virginia University \\ in partial fulfillment of the requirements for the degree of \\ Doctor of Education in \\ Special Education, Personnel Preparation in Special Education
}

\author{
Kimberly Floyd, PhD, Chair \\ Michael Mayton, PhD, BCBA-D \\ Neal Shambaugh, PhD \\ Colleen Wood-Fields, PhD \\ Department of Special Education
}

\author{
Morgantown, West Virginia \\ 2017
}

Keywords: Parental supports, access to services, barriers in rural settings, family stress Copyright 2017 Erica Curington 


\section{ABSTRACT \\ Beyond the classroom: The need for support for parents with a child diagnosed with autism, ID, and behavioral problems}

\section{Erica Curington}

Families with individuals with special needs face many different struggles such as identifying needs and/or appropriate supports, accessing those supports, and then locating providers to help implement those supports (Boehm \& Carter, 2016). These individuals may need continuous support to live meaningful and productive lives outside of the classroom. As students leave the classroom, the need for addressing these struggles becomes of greater value and difficulty for families. This is especially true in more rural areas due to lack of services. The following research questions were utilized during this study: What services have been used outside of the classroom to address the needs of your child? What barriers have you encountered when attempting to access these services? What changes in your child's behavior have occurred since having access to the necessary supports? A case study interview was conducted with family members of two individuals that have been diagnosed with Autism, a Moderate Intellectual Disability, Attention Deficit Hyperactivity Disorder, and Intermittent Explosive Disorder in a more rural setting. In regards to services used outside of the classroom to address individual needs, the study found that the initial experience with accessing supports and the process of determining service acquisition was very emotional and stressful for both families. Barriers encountered when attempting to access the appropriate supports outside of the classroom became frustrating due to a lack of understanding of how to appropriately locate the services available, as well as fully understanding the diagnoses rendered. The changes in the participant's behaviors were less stressful once having access to the necessary supports, and the family's abilities to understand their child's needs was also improved. Implication of the study is that supports provided more knowledge which in turn provided a better understanding from family members. 


\section{Table of Contents}

Introduction and Purpose $\quad 1$

Brief Literature Review

Identification of Supports $\quad 1$

Access to Supports $\quad 3$

Implementation of Supports $\quad 4$

Barriers to Supports in Rural Settings

Design

$\begin{array}{ll}\text { Overview of Study } & 6\end{array}$

$\begin{array}{ll}\text { Participants } & 7\end{array}$

Data Source $\quad 8$

Data Collection Procedures $\quad 9$

Data Analysis Procedures $\quad 10$

Results and Discussion 11

Implications and Recommendations $\quad 19$

$\begin{array}{ll}\text { Future Research } & 23\end{array}$

Limitations $\quad 24$

$\begin{array}{ll}\text { Conclusion } & 25\end{array}$

$\begin{array}{ll}\text { References } & 27\end{array}$

$\begin{array}{ll}\text { Appendix } & 31\end{array}$ 


\section{Introduction and Purpose}

Today, families with individuals with special needs face many different struggles such as identifying appropriate supports, accessing those supports, and then locating providers to help implement those supports (Boehm \& Carter, 2016). There is a lot of misinformation on providing individuals diagnosed with special needs the services and supports they need. There is a perception that these individuals are receiving those services from school. Many disparities are discussed, but little research that focuses on how families are unable to access the appropriate services to address individual needs (Evans, Feit, \& Trent, 2016). In fact Nachshen, Woodford, and Minnes (2003) created a Family Stress and Coping Interview to examine the experiences of parents with children with developmental disabilities. They researched the stress related to locating services based on disability identification and developing coping skills based on parents' age and length of time dealing with the child's disability. However, their needs continue beyond the school day, and they may need continuous support to live meaningful and productive lives outside of the classroom. In other words, "families are an instrumental part of service coordination and delivery" (Weiss \& Lunsky, 2010, p. 146). Therefore, it is important to provide families with the knowledge of different options in order to assist in effectively addressing their children's needs. In fact, legal mandates provided by the Individuals with Disabilities Education Act (IDEA), ensure that transition services are included in all Individualized Education Plans (IEP) when the student is sixteen years old, and may be included earlier if appropriate (Bateman, 2004). As students leave the classroom, the need for addressing these struggles becomes of greater value and difficulty for families. Especially if these mandates are not withheld or understood by the school personnel developing and delivering this information.

\section{Identification of Supports}


It is understood that families who have children with disabilities experience higher levels of stress (Auyeung, Burbidge \& Minnes, 2011). Even though there are many factors that can contribute to this stress, a main contributing factor is the many barriers these families face when identifying the appropriate and available resources available (Boehm \& Carter, 2016). Services such as respite, developmental therapy, social support, and community activities are commonly needed supports, but ones that often go un-provided due to the inability of families to understand, locate, and afford them (Heller, Caldwell \& Factor, 2007). The field of health care and services for parents to access is constantly growing, and it can become a daunting task for families to identify relevant services and acquire information to further explain them. The school system is an obvious solution to this problem, but one that doesn't always come to fruition. "Transition services are a coordinated set of activities that promote movement from school to such post-school activities as post-secondary education, vocational training, employment, adult services, independent living and community participation. They must be based on the individual student's needs, taking into account his or her preferences and interests" (Bateman, 2004). When this critical part of planning is ignored, parents continue to struggle with identifying the appropriate supports their children need. With little knowledge and experience, many families continue to independently support their family members with disabilities because it is viewed as 'easier'. However, services should be not only identified, but also developed to support these families in all areas needed (Mulligan, John, Coombes, \& Singh, 2014). Douma, Dekker, and Koot (2006) completed an assessment of support needs of parents using the Need for Help Questionnaire and discovered that less than half of parents requiring supports received them. It has been well established that when needs go unmet for individuals with intellectual disabilities, they become at greater risk of developing other mental health 
problems or challenging behaviors (Cooper, Smiley, Morrison, Williamson \& Allan, 2007).

When these issues arise, it is a clear reflection of the gap between the needs of the individual and the inadequacy of supports being provided. It is important to understand the experiences of these families in order to be able to address the inequities of services being delivered to this population.

\section{Access to Supports}

Personal experiences and attitudes of parents also influence their decisions to seek support(s) (Kerkorian, McKay \& Bannon, 2006). Negative encounters with providers, inability to locate information, and difficulty getting services initiated are all reasons reported by parents expressing their inability to begin or access services (Bailey \& Scarborough, 2003). The sector of individuals that seem to have the most difficulty accessing services are school aged and those no longer attending school daily (Weiss \& Lunsky, 2010). The services that they come in contact with are more reactive in nature, as opposed to proactive. These families want to be able to provide their individuals with on-going care and not just care during crisis situations. This issue of care reflects the importance of regular access to necessary supports for individuals with disabilities and the prevalence of inadequate delivery of services. "The prevention and treatment of disabilities in children are imperative to child health" (Evans, Feit, \& Trent, 2016, p. 97). There are legal statutes that emphasize helping families gain access to the resources and skills needed to meet the needs of their child(ren) with a disability.

"The legal significance of transition, being but one aspect of the IEP process, is substantial. A student is entitled to those transition services which for that student are either special education or related services necessary to enable the student to benefit from special 
education. The period of "benefit" to be considered has arguably been lengthened beyond school and into adult life" (Bateman, 2004). Through IDEA, the federal government has developed several projects and initiatives to help identify effective transition practices. These practices have been aimed at schools, community agencies, and other transition personnel to help promote outcomes for students with disabilities after they leave the school setting. Although these practices were thought to be a sounding board for all involved in an individual's transition, there was little "empirical evidence" to help support them and allow appropriate and adequate application. After the reauthorization of IDEA, several studies and review of previous transition literature were completed. Through these reviews, "best practices" of the transition services through IDEA were identified as "interagency collaboration and interdisciplinary collaboration" (Landmark, Ju, \& Zang, 2010, p. 166). This is important due to the preparation of future transition(s) and the identification of supports during this process. However, the continued lack of collaboration skills and family-centered practices complicates access to appropriate supports for individuals seeking parent-professional partnerships. These continued challenges deter families from being able and wanting to seek vital supports and resources for individuals in their families that need them.

\section{Implementation of Supports}

There are gaps in effective methods for providing supports, but a multidisciplinary collaborative approach was discovered by Mack (2008) that enables providers to be able to achieve identification as well as intervention implementation in unison. "Developing services to enhance the quality of life for the entire family suggests the need for multimodal interventions" (Mulligan, John, Coombes, \& Singh, 2014, p. 162). Evidenced-based practices are emphasized when actively supporting individuals and their families. This means the providers use "what 
works" in their operations (Webster, 2009, p. 215). The practices used during transition planning such as integration and community based instruction are an integral part of the process of addressing the IDEA transition services being put into place. These are requirements that should be provided regardless of location, previous educational supports, and parental knowledge based on the reauthorization of IDEA in 1997 and 2004 (Landmark, Ju, \& Zang, 2010). When IDEA mandated transition services are not implemented or monitored the possibility of success is increasingly diminished (Sutton, 2013). It is important to develop an effective support system that includes problem-focused strategies within the actual implementation of supports. This enables the team to utilize positive coping techniques to work together and help support the individual in the best means possible (Mount \& Dillon, 2014). If not, the transition process becomes skewed and is no longer effective or results-oriented.

We know the field of disability services is not a 'one size fits all' model and requires new implementation of ideas to help diversify and develop new strategies for a wide variety of disability areas and individuals. Services and supports are identified through plans and appropriate resources can then be developed (Lynch \& Hanson, 1998), which allows all individuals to be supported in their "own" way and a way in which best meets their needs. Appropriate implementation of supports can be the beginning of an enhanced quality of life for an individual with a disability and one's family (Evans, Feit, \& Trent, 2016).

\section{Barriers to Supports in Rural Settings}

There has been a historical challenge of not only accessing, but retaining services for individuals with disabilities in more rural settings. "Geographic isolation, professional isolation, diversity of caseloads" and "shortage of highly qualified professionals" are all characteristics 
used to describe the barriers faced when in more rural areas (Berry \& Gravelle, 2013, p. 1). These factors only add to the frustration of the lack of follow through with transition planning and the need for services for students beyond the classroom. The lack of community based services prohibits individuals from obtaining the needed and research based interventions that could offer support to them and their families.

The ability to retain appropriate services allows for "engagement, positive social interactions at home and the community, as well as enhances the quality of life" (Dew, Bulkeley, Veitch, Bundy, Gallego, Lincoln, Brentnall, Griffiths, 2013, p. 1565). The fact that children continue to go without the benefits of these services due to lack of access is disappointing and further supports the need for additional resources and research in rural settings. Especially when it comes to following rules and regulations within the school system. Something that parents are dependent upon with guiding them in the right direction(s) for services for their children.

\section{Design}

\section{Overview of Study}

A case study of two families provided the unit of analysis. Individual family interviews served as the source of data for this study. Interviews of family members took place in their home to determine the supports the family has accessed outside of the classroom, the barriers they faced when attempting to access these supports, and changes in the child's behavior and family unit as a result of these supports. The interview prompts were adapted from The Need for Help Questionnaire by Douma, Dekker, and Koot (2006). This questionnaire was selected specifically because it looked at the families need(s) for support(s) and whether these needs were met. A second interview protocol, an adaptation of the Family Stress and Coping Interview by 
Nachshen, Woodford, and Minnes (2003), was used by the researcher to better understand potential coding categories that might emerge from the interview because of the examination of stress related to family experiences of those with children with disabilities. The identification of themes support the data reduction techniques of Miles and Huberman (1994).

\section{Participants}

The subjects participating in this study are two different families with an individual that has been diagnosed with Autism, a Moderate Intellectual Disability, Attention Deficit Hyperactivity Disorder, and Intermittent Explosive Disorder. Both families live in a southern region, but in two different counties. This was a convenience sample due to the researcher working with both families in regards to support services coordination. These families were chosen due to both having sons with the same identification and unique perspectives on the lack and advantage of having access and experience with appropriate services for their sons.

Sean (pseudonym) was eighteen at the time of the interview with his family. The family unit included the child living at home with his mother, father, and younger sister (age ten). The interview was conducted with Sean's mother and father: Sean did not participate. This family is considered to be middle/upper middle class, and his father is a college graduate. Sean attends high school in a self-contained Autism classroom in a positively rated school district based on Niche. Niche is a website that "rigorously analyzes dozens of public data sets and millions of reviews to produce comprehensive rankings, report cards, and profiles" of schools in the United States (Methodology for Niche K12 Rankings, 2017). Aside from Speech and Language and Occupational Therapy services received during the school day, Sean did not receive other services. Sean was originally given a diagnosis of a speech disorder at age three. This was due to him not talking and only repeating; however, there was no other mention of any other 
developmental disorder(s). At age five, he was given a diagnosis of Pervasive Developmental Disorder (PDD), but was not identified as being on the Autism Spectrum until he was nine years old. Throughout the years, parent shad difficulty receiving appropriate school services. There was no integration and/or inclusion opportunities for many years. At sixteen years old, Sean began to develop more aggressive behaviors. He became increasingly violent and physical, especially towards his mother and his sister. These behaviors included hitting, kicking, pushing, biting, and cursing. Sean's level of Intellectual Disability is diagnosed as Moderate.

Chris (pseudonym) was twenty-one at the time of the interview. The interview was completed with Chris' mother only. The family unit included the child and his mother living together. This family is considered to be lower/working class, and mom is a high school graduate. Chris no longer attends school, but if enrolled, would attend a moderately rated school district based on Niche. Aside from Speech and Language, Physical, and Occupational Therapy services received during the school day, Chris received services outside of the school since he was four years old. At age two, Chris was taken to his primary care physician due to his inability to walk. He was dismissed, but referred to a Neurologist for additional testing. Results were also negative, so he was then referred to a local evaluation center. It was at two and a half years old when Chris was originally diagnosed with Autism, but this diagnosis was confirmed again at three years old when evaluated at a Speech/Language Therapy Center. Due to Early Intervention services, services were able to connect quickly for Chris. Chris' level of Intellectual Disability is diagnosed as Severe/Profound.

\section{Data Source}

The source for the data was an interview with family members, concentrating on the individuals' parents. Interviews were used to determine the supports the families have accessed 
outside of the classroom and the barriers they have faced. The interview sessions were conducted using five main prompts to answer the study's three research questions. Interview questions were developed from the Douma (2006) and Nachshen (2003) interview protocols. Health care inequities have been identified all over the world for those individuals with Intellectual Disabilities and the provision of supports (Dekker \& Koot, 2003). The Need for Help Questionnaire was developed to further investigate the support needs of parents of children diagnosed with an Intellectual Disability that also experienced behavioral and/or emotional problems. When the receipt of services was "less than half" of parents actually needing them, Douma decided to further investigate the barriers of service receipt (Weiss \& Lunsky, 2010, p. 147).

The five main prompts include the following: specific features of each question are recorded in Appendix (Interview 1).

1. Parent perception of problems: crises/major concerns, diagnoses, serious problems.

2. Need for support: to what extent did you need support in the past year because of, or related to, the crisis/major concerns?

3. Met need and effectiveness of support: if support was needed, was it received, and to what extent were you satisfied?

4. Barriers to support.

5. Sharing of story.

\section{Data Collection Procedures}

One interview was conducted with each family. The sessions included enough time needed to ask and record their responses to the five main prompts. The interviews took place at the families' homes, which allowed the individuals to be in their own surroundings during the 
interview sessions and provided a convenience for the family. The predominant interviewees were Sean's mother and father and Chris' mother. The interviews were voice recorded.

\section{Data Analysis Procedures}

The interviews were recorded and later transcribed. The transcriptions were reviewed for accuracy and detail. The data analysis used the data reduction strategies of Miles and Huberman (1994). An initial reading by each reviewer was completed independently in order to gain an overall impression and feel for the data. During the second reading, each reviewer identified initial themes. On a third reading, responses were assigned to appropriate themes. On a final read, salient quotes were noted.

From the written transcript of the interview, specific items were recorded in a table for each interview question (see Appendix). For example, for interview question 2 the researcher recorded in a table the extent of need for specific supports, including listener, information, child activities, care, financial aid, or counseling. The procedure extracted specific information from the dense interview transcript to the table for further data reduction and understanding.

The fifth interview question asked the family member(s) to cite a memorable story around key incidents of need and attempted support. Within this story, the researcher highlighted in the transcript references based on the three research questions. The narrative included specific details, not obtained from other questions, which helped to answer the three research questions involving need for support, effectiveness of support, and barriers.

At this stage the information recorded in the table was utilized to answer the three research questions (see Table 1). Multiple interview questions help to answer each of the three research questions. Research question 1 regarding services used is answered from responses to interview questions 1,2 , and 5 . Research question 2 on barriers to supports may come from 
interview questions 4 and 5. Research question 3 can be answered from examining the table for items from interview questions 3 and 5. The major source of data to answer each of the research questions may come from one interview question, but may be supported by additional questions as shown in Table 1. In particular, the story contributed some support in answering each of the three research questions.

Table 1

Match of interview question with research question

\begin{tabular}{ll}
\hline \multicolumn{1}{c}{ Research Question } & \multicolumn{1}{c}{$\underline{\text { Interview Question }}$} \\
$\begin{array}{ll}\text { RQ1: What services have been used outside } \\
\text { of the classroom to address the needs of your }\end{array}$ & Q1: Parent perception of problems: crises and \\
child? & Q2: Need for support. \\
& Q5: Sharing of story. \\
RQ2: What barriers have you encountered & Q4: Barriers to support. \\
when attempting to access these services? & Q5: Sharing of story. \\
RQ3: What changes in your child's behavior & Q3: Met need and effectiveness of support. \\
have occurred since having access to the & Q5: Sharing of story. \\
necessary supports?
\end{tabular}

\section{Results and Discussion}

Each research question can be answered based on information recorded in the data reduction table (see Appendix). The results and discussion will be organized around each research question addressing family support experiences, support barriers, and results of support use.

RQ1: What supports have been accessed outside of the classroom to address the needs of an individual diagnosed with Autism, ID, and Behavioral Problems? 
Given the response(s) from the participants regarding their personal experience with accessing supports to address the needs of their child, the initial process was very emotional and stressful for both. However, Sean's family leaned more towards expressing information related to the lack of access to services. "He's fine. He's gonna grow out of it. He does talk. He's not Autistic. Look, he talks" (Sean's Mother). At age three he was not talking and would only repeat others. Sean's mother remarking on his initial communication, "He repeated everything that we said. That's not right, you know, and even though we went to the doctors, they didn't say to us Autism. This was never an issue. We didn't say that he was Autistic. They didn't bring that to us, but when I got him in school they said once he was exposed to other kids, this probably will go away." Although the parents noted that their son did not improve, it was up to them to reach out to the program to access assistance. Sean's father remembering those earlier days, "I went to the director. And she was like I'm so glad you brought it to our attention because we noticed the same thing, but we wanted you to come to us. We were so upset because I'd rather you some to me so I can say okay, what can we do?" Soon after, Sean was initially given a diagnosis of a speech disorder due to his inability to verbally express himself. He was not given a full diagnosis until he was five and this was for Pervasive Development Disorder (PDD). While this diagnosis registered on the Autism Spectrum in two different places, he was not given a confirmed diagnosis of Autism Spectrum Disorder until he was nine years old. There were little to no options made available to them outside of the classroom for years. According to Sean's father, "We have no help, no advice. We were just on our own with this". In fact, their son only had access to Occupational Therapy and Speech and Language Therapy services during the school day for almost eighteen years. They even tried year round schooling with no success, which then lead them to keeping him home for months due to unavailability of proper resources 
at their current districted school until they contacted someone only identified as having political connections. Sean's father reaction to that engagement, "Clearly you could have done something because you did. You did after that phone call came in." They knew something had to be done. However, the ability to access supports outside of the classroom became all the more frustrating because they felt as though they were never without crisis situations. Trying to understand these needs became a confusing waiting game, and all they wanted was a clear understanding of the needs of their child. The intensity and frequency of his behaviors increased at home. Sean's mother shared, "He would just throw things. He would run down the street. You would have to chase him. He was just yelling, using curse words." Therefore, making the need for supports to become crucial and personal. In fact, there was one situation in which the local police were called for help. The individual had become increasingly more violent and physical. This particular time, his mom was the victim of a very aggressive episode. The individual was admitted to the emergency department and then referred to an acute in-patient program that specializes in behavioral healthcare. The individual was there for one week. When he returned home, he began eloping and his behaviors were very unpredictable, which triggered a request from a Psychiatrist for assistance. The request went to a Local Management Entity/Managed Care Organization (LME/MCO). The purpose of a LME/MCO is to provide mental health, intellectual and developmental disability, and substance use services to individuals in their catchment area. Due to the request, along with supporting documentation (such as discharge summaries, psychological evaluation, and education history), the request was granted and the individual was granted an emergency slot for assistance. Sean was eighteen years old at the time. Armed with the support of professionals, Sean was able to access Assistive Technology, Community Living and Supports, Respite, and Specialized Consultative Services. Assistive 
Technology enables equipment to be purchased to assist with daily tasks. Community Living and Supports is a service that helps the individual become more independent, work on specific skills, learn how to manage his daily living activities, and also have extra support for health and safety reasons. Respite provides the family relief from caregiver stress and responsibilities. Specialized Consultative Services (SCS) provides family and staff with education and training in a specialty area (i.e. psychology, occupational therapy, physical therapy, etc.). SCS also allows evaluations for individual specialized equipment (i.e. assistive technology, home modifications, etc.) ("NC Innovations Waiver Services", 2017). Both Sean's mother and father agreed that their life is "absolutely less stressful" for their family since their child now has all of the services he needs.

Chris' family had a different experience. His family leaned towards the opposite end of service acquisition compared to Sean and speaks to more success of accessing services. While both families were initially dismissed by their primary care provider, Chris was referred to a Neurologist. Once nothing was identified, the family was then referred to a local evaluation center to see if they could get more information in regards to why negative results were given in the various medical evaluations/tests attempted (i.e. MRIs, X-rays, blood work, etc). At the local evaluation center, Chris began receiving Physical Therapy to assist with walking. Within a few months, he was walking and continued to perform well on all assessments completed in-house at this development center. At this time, he was given a diagnosis of Autism Spectrum Disorder and referred to another local center specializing in Autism Spectrum Disorders. Therapists and case workers began working with him providing Early Intervention Services, and his family would watch and learn as well. They also saw other individuals receiving additional services (and for longer periods of time) and began to inquire 'why' and 'how' they were able to do so. 
Chris' mother reflects, “There was some kids that was getting 2-3 times a week, and I couldn’t understand. What's going on? I even called the director. I wanted to know what was going on with that. How come they can get that and I can't?" Soon after, the family was referred to the Client Assistance Program (CAP). The purpose of CAP is to assist individuals with disabilities in understanding and using rehabilitation services available to them based on need and medical necessity. At this time, the request was sent to a local mental health program and he was awarded a slot to begin receiving services. Chris was four years old at the time. His mother stated, "I called the case manager, the director and she saw what was going on. And she says well we have 2 slots left and we're going to let you have one. Honey I jumped up and down. I didn't mean to, but I jumped all up and I squealed and I hugged her and I says thank you so much. I started crying." His services are now managed by a LME/MCO and he is able to access Assistive Technology, Community Living and Supports, and Respite. Similar to Participant One, the Assistive Technology enables equipment to be purchased to assist with his tasks of daily living. Chris' mother stated, 'Honey, I don't know what I'd of done if it hadn't been for his therapist and the people that would split his care. Honey I'd been a blank page." She is very thankful for the services her child has received over the years.

In summary, both families sought out their physician's due to concerns they had with their child's behavior. However, neither were acknowledged as being grave concerns. Sean's family was told his repetition of words would go away once exposed to more structure at preschool. Chris was referred for additional testing, which resulted in negative findings, but did include an additional reference to an evaluation center for therapy to assist with walking. Once there, Chris was able to receive therapy and began receiving community supports at the age of 
four years old. Sean continued with no support or services until he was granted emergency assistance due to his explosive behaviors at eighteen years old.

Based on review of the literature, information from this question supports the need for continued identification of supports. Families of individuals with disabilities experience higher levels of stress due to various barriers with resource acquisition. Therefore, services continue to go un-provided due to the inability of families to understand, locate, and afford them (Heller, Caldwell \& Factor, 2007). Service inequity needs to be addressed through further investigation. RQ2: What barriers have been faced when attempting to access these supports?

Fifteen years is a long time to wait to access appropriate services for any individual, but for Sean's family, that is exactly what occurred. Initially, the family thought that the issue(s) might be temporary and not too serious because their child could communicate with them. His mother reflecting on her initial thoughts surrounding his lack of appropriate expressive communication, “I don't know and he would tell you, I don't know. It breaks your heart because he cannot tell you what's going on." However, as time passed his parents began to conform to this "life" and catered to their son, and created a bubble for their other child to live in. There were no fears of labels/stigmas, they simply wanted an answer. Family was uncertain as to what was going on, so the next step was to seek professional help. Sean's father's frustration is demonstrated with "You're asking for help and support and you're running up in a brick wall". During this time there were numerous negative experiences with multiple professional(s). Examples highlighted were wait times in diagnosis and services for their son, but also when actually attending appointments, both in and out of the actual examination room, and not knowing who/where to go because there was no help provided. His father stated, "It was, it was pretty bad. It was very stressful." The steps to begin seeking help and information were 
overwhelming because the parents were unaware of the appropriate services and the funding options available.

For Chris, services appeared to connect rather easily. However, due to the unknown and unfamiliarity with his diagnosis, the family was left with little clarity and an immediate dependence on others to show them how to navigate 'the system' and find the right professionals to work with. Through life experiences, the family was able to receive exposure and made sure to be present during therapies and services provided. His mother stated, "I learned how to start off by watching the therapist. They taught me." With this, they were able to gain the knowledge needed to help him learn the way that best suited his needs. However, this also resulted in an inner dependence and fear of being a burden to others when assistance was needed. Chris' mother reflects, "I mean, I don't feel like I can just dump it on my daughter." Since obtaining services, there have been issues with staffing, distance to receive help, and locating appropriate opportunities for him to participate in. His behaviors and the newly acquired medical diagnoses were also mentioned as an on-going challenge. The steps in the beginning seemed to be a bit more stressful then how things are playing out now, especially due to the early acquisition of assistance and access to appropriate services. "Cause honey, mine jumped just like a bouncing ball - one thing to the other. Connect, connect, connect, connect" stated Chris' mother.

In summary, Sean's family thought his issues may be temporary and adapted to the way things were. With doing so, they faced many barriers and had many negative experiences with a variety of professionals and continued to struggle with locating appropriate services and funding options available for their son. Chris' mother's main barrier was her unfamiliarity with his diagnosis. However, with services rendered, she was able to learn more by the therapists 
involved in Chris' care. She did rely on the professionals working with her son, and continued to struggle with navigating the different supports needed and opportunities available.

Based on review of the literature, information from this question extends the need for appropriate access to services. Negative encounters with providers, inability to locate information, and difficulty getting services initiated are among the top reasons as to why families continue to go without (Bailey \& Scarborough, 2003). The largest populations that go without appropriate access are school aged and those no longer attending school on a daily basis. Families want to provide on-going care, but continued lack of collaboration complicates access to appropriate supports even more.

IDEA mandates that are not enforced contradict expectations, resulting in continued challenges that deter families from seeking vital supports. In addition, the historical challenges for rural settings continue to be in effect and require additional resources and research. RQ3: What has changed since having access to the necessary supports?

Even though the services accessed are new for Sean and had been established for Chris, both of the participants' families are very thankful. The daily stress experienced now is minor compared to how things were months and even years ago. There are no stress-related issues to the actual diagnoses, aside from typical behavioral and medical concerns. "Alright so it took me a while to get on. Listen, this is what we've got, so we're gonna deal with it" stated Sean's mother. Now that the families have answers, each have more knowledge and are creating a better understanding of what their son needs every day. Chris' mother said it best when she stated, "I can do more. Knowledge is power you know?"

In summary, the ability to access and work with a variety of professionals is one of more ease. The families and even supports are constantly learning about new opportunities and 
experiences that the individuals can participate in. The level of integration depends on the individual's behaviors and interests, but even that seems to be expanding. With supports in place, the families are able to breathe a little easier knowing that services are (and have been) being provided and they are both getting the support(s) that they need. Both families are still working on developing friendships/relationships with other families. It is important for families to have connection with the community and outside resources. Access to both goes a long way to reducing stress and increasing positive outcomes for the child. In rural settings, access may be limited to distance from school or other community activities. Therefore, connections by knowledgeable professionals is of utmost importance.

Based on review of the literature, information from this question contradicts the assumption that transition services and other supports are readily available and in place. The divide in effective methods for providing supports still exists (Mack, 2008). Due to the inability for disability services to be uniform for everyone, new ideas and strategies are still very much needed (Mulligan, John, Coombes, \& Singh, 2014). This idea further supports the development of on-going research to enhance and/or revise current evidence-based practices.

\section{Implications and Recommendations}

Implications of the study are that when supports are provided to individuals with disabilities, more knowledge is acquired. This in turn provides a better understanding to the family members. Access to services and supports reduces stress and increase positive outcomes for the individuals and their families. Also, in rural settings, access and connections by knowledgeable professionals is of utmost importance. 
Some recommendations that have resulted in this study are in reference to service providers, school personnel, and parents. The following are suggestions that should be provided for each population:

\section{Service Providers}

Better questionnaires and assessments are needed to determine the needs of individuals and their families. Initially, it doesn't seem that either family was asked about their concerns. Instead, they were simply dismissed. More in-depth questions that could identify or at least assist with directing their concerns to the most appropriate service provider could have helped both the families and primary physician. The ability to provide questions/prompts that pertain to certain areas, could also address the needs of the families more specifically as opposed to globally.

The provision of earlier intervention procedures could also assist service providers with addressing concerns. Of course there are many reasons why parents seek out professional help, but the ability to intervene earlier would assist in identifying developmental and cognitive delays, as well as linking to appropriate services. This could also assist in decreasing over diagnosing and inappropriately utilizing resources. If appropriate Child Find initiatives are in place and the physicians/pediatricians have received adequate education and training, their ability to not only appropriately identify, but also link to services is significantly increased. The need for better education for families of children and individuals identified with disabilities is also very much needed. Families are often dependent on service providers to guide them through the processes of obtaining appropriate supports. If better information is provided, then the ability to start in the right direction becomes one more of ease and will hopefully lead to positive outcomes. Once identification occurs, there should be an immediate connection with 
early intervention services. Dependent upon age of identification, there are mandates that require follow-up with the pediatrician to ensure early intervention services have occurred before the age of three, connections with local special education preschool programs for children under the age of five, and if identifications occurs once the child is school-aged, the school system becomes responsible for linking with appropriate supports and services needed within the school day.

\section{School Personnel}

First and foremost, the adherence and appropriate implementation of IEPs for all students is crucial. Not only should this information be covered in teacher preparation courses, but continued education and training should be provided for all school personnel. A variety of inservices on the IEP and transition planning processes is a start. This would allow a more fluid approach to not only transition planning, but all special education services while in the school setting. Involving teachers, administrators, school social workers, counselors, and therapists enables the collaboration and person-centered strategies to be fully developed and enhance the quality of life for each student and their future endeavors.

In addition to fully understanding one's IEP and the individualized supports needed for students with disabilities, comes an even greater need for a clear implementation of IDEA mandates that coincide. The fact that these legal provisions are being overlooked and not upheld, is gravely concerning. There should be initial and annual in-services provided to all school personnel. This information should also be shared openly with parents to ensure they understand their student's rights. Appropriate application and implementation of these mandates is important and only helps enhance the outcomes for each individual. 
If better education is provided, then more thorough follow through with service transitions is possible. Again, this is a collaborative approach that should be interdisciplinary to cover a wide variety of needs and service professionals. We've established that disability services is not the same for everyone; therefore, neither should transition planning. This allows all team members to be a vital part of appropriately developing transition services.

\section{Parents}

A survey should be developed with focused questions addressing specific concerns with optional follow-through recommendations for Primary Care Providers and a required follow period for answers, solutions, or appointments to organizations or other personnel able to provide the child's needed support. This not only allows the parents to pinpoint their concerns, but also assists the physician or pediatrician in appropriately assisting the parents and families. Having a better way to display and encourage open discussion amongst families could really assist with accurately identifying areas of need.

The need for better access to the most appropriate services is also crucial. Oftentimes, parents are unsure of what to do once a diagnosis has been given. Combining the educational information with "family-friendly" language allows for better understanding of how to successfully begin to navigate services. Also, utilizing state-wide established resources such as the Department of Health and Human Services Division of Child Development and Early Education enables parents to get connected with the Family Support Network, as well as access a directory that houses a database of information pertaining to disability/illness, resource contact information, and various support programs in various parts of the state. Other links available are Disability Right's, Exceptional Children's Division of Department of Public Instruction, Children's Developmental Services Agencies (CDSA), and The National Information Center for 
Children and Youth with Disabilities (NICHCY). All of these provide comprehensive information to assist youth with disabilities and their families.

\section{Future Research}

In addition to the recommendations made above, further research is still needed. Ideas that could build upon the information resulted from this study are reviewing resource allocation in terms of investigating the amount of funds provided to LME/MCOs and the number of individuals served versus the number of individuals on waiting list(s). The need for services is there; however, the waitlist for individuals to receive assistance from local state agencies is outstanding. Some families have been on the waitlist for years. A possible way to review this information would be to analyze the amount of funds that are granted from the federal government annually. This could assist in budgeting, appropriate allocation, and utilization of resources in regards to the LME/MCOs and the current individuals served. Comparing the amount of money granted to the amount of money spent, would possibly reveal availability of funds. Instead of having excess funds sitting in an account, they could be used to provide needed supports to families of individuals currently on the waiting list.

A study of the availability and utilization of early intervention services for all children entering preschool is also needed due to the high amount of individuals undiagnosed, as well as services un-rendered. Simply reviewing the number of children applying for early intervention services to the number of children entering preschool, would allow a closer look at the proportions. Being able to analyze these numbers would provide service providers and school personnel a better plan to manage and track services needed and provided for both the upcoming and currently enrolled preschool population. 
An in-depth look at service delivery (according to census) to determine where and what outreach is needed and what services are currently being utilized is crucial. Surveying different regions would allow services to be accounted for according to service area. This could also reveal that an increase in services, as well as the level of care are provided in certain areas (closer to major medical and educational institutions) is higher and the distance individuals in more rural settings have to travel in order to access these services is much farther. This information could assist in a directory of resources for parents and families, in addition to agencies when determining future areas for service delivery.

The need to study service provider retention in rural settings is also heavily needed to help combat the turnover rate of service delivery by said providers. Again, surveying different regions would account for services provided and the actual providers per area. Once available, information could be populated by LME/MCOs to determine the number of services billed per provider. This would allow for a trend to be analyzed to review what and how much is actually being provided (and by who), as well as determine possible antecedents for turnover in these settings. This information could assist providers and other referring agencies when developing a plan of care for those living in less densely populated areas.

All of these are areas of concern and hold potential benefits that could greatly support children and their families.

\section{Limitations}

One limitation is the case study design that includes the participation of only two families. This limitation was addressed by confirming the availability and willingness to participate in this study using consents. Another limitation is the use of one modified questionnaire and adapted interview. To address this limitation, the participants were 
interviewed in their own environment, prompting them to be comfortable which hopefully enhanced their ability and desire to be open and honest when responding. The final limitation was the lack of generalization of results. Both families were from rural settings, so a comparison to urban environments and opportunities was not investigated.

\section{Conclusion}

Understanding the struggle that many families with individuals with special needs encounter with identifying appropriate supports, accessing those supports, and locating providers to implement those supports is important. All of these barriers affect the stress levels of families and can be difficult to understand and acquire (Auyeung, Burbidge \& Minnes, 2011). In previous literature, Douma Dekker, and Koot (2006) found that less than half of parents with children with disabilities actually received the supports they needed using The Need for Help Questionnaire. Providing individuals diagnosed with special needs the services and supports they deserve should not be a misleading or confusing process. However, many families have negative experiences with accessing the necessary supports and therefore choose to go without or delay service acquisition (Bailey \& Scarborough, 2003). The need to focus on the quality of life not only of the individuals but also their families, means implementing supports that use a variety of research based interventions that enables a team to work together and create a cohesive environment for treatment (Mulligan, John, Coombes, \& Singh, 2014). The research that focuses on these needs and how these families are unable to access the appropriate services is still needed, especially in more rural settings. The historical issues of accessing and retaining community based services in these areas are inhibitors to individuals and their families (Dew, Bulkeley, Veitch, Bundy, Gallego, Lincoln, Brentnall, Griffiths, 2013). Based on the results, the experience with accessing supports and the process of determining service acquisition was very 
emotional and stressful for both families in reference to addressing services outside of the classroom for Sean and Chris' individual needs. Sean's family experienced fifteen years of struggles with not only receiving a diagnosis, but acquiring the necessary supports for him and his family. Chris's services were able to align more quickly, but his family still struggles with accessing appropriate supports and/or opportunities due to his geographic location. Other barriers were also encountered when attempting to access the appropriate supports outside of the classroom. This process became frustrating due to a lack of understanding of how to appropriately locate the services available, as well as fully understanding the diagnoses rendered. Sean's family was initially under the impression that he would grow out of it, or it would go away. While Chris' mother became increasingly dependent on others to help guide her through this process. However, once supports were in place, the changes in both Sean and Chris' behaviors were less stressful for their families. Having access to the necessary supports enhanced the families' abilities to understand their child's needs. This study could prompt further research and additional insight into assisting families to obtain the services and supports they need. The information provided from the interviews with these two families is very powerful and further stresses the importance of services and supports needed not only in rural areas, but for all families of children with disabilities at the onset of diagnosis. 


\section{References}

Auyeung, K., Burbidge, J. \& Minnes, P. (2011). Perceived parental stress: The relative contributions of child and parent characteristics. Journal on Developmental Disabilities, $17(2), 10-20$.

Bateman, B. (2004). Legal requirements for transition components of the IEP. Wrightslaw. Retrieved from http://www.wrightslaw.com/info/trans.legal.bateman.htm.

Berry A. \& Gravelle, M. (2013). The benefits and challenges of special education positions in rural settings: Listening to the teachers. The Rural Educator, 34(2), 1-13.

Boehm, T.L. \& Carter, E. W. (2016). A systematic review of informal relationships among parents of individuals with intellectual disability or autism. Research and Practice for Persons with Severe Disabilities, 41(3), 173-190.

Cooper, S., Smiley, E., Morrison, J., Williamson, A. \& Allan, L. (2007). Mental ill-health in adults with intellectual disabilities: Prevalence and associated factors. British Journal of Psychiatry, 190(1), 27-35.

Dekker, M.C. \& Koot, H.M. (2003). DSM-IV disorders in children with borderline to moderate intellectual disability: I. Prevalence and impact. Journal of the American Academy of Child \& Adolescent Psychiatry, 42, 915-922.

Dew, A., Bulkeley, K., Weitch, C., Bundy, A., Gallego, G., Lincoln, M., Brentnall, J., Griffiths, S. (2013). Addressing the barriers to accessing therapy services in rural and remote areas. Disability and Rehabilitation, 35(18), 1564-1570. 
Douma, J.C.H., Dekker, M.C. \& Koot, H.M. (2006). Supporting parents of youths with intellectual disabilities and psychopathology. Journal of Intellectual Disability Research, $50,570-581$.

Evans, D.L, Feit, M.D. \& Trent, T. (2016). African American parents and attitudes about child disability and early intervention services. Journal of Social Service Research, 42(1), 96112.

Heller, T., Caldwell, J. \& Factor, A. (2007). Aging family caregivers: Policies and practices. Mental Retardation and Developmental Disabilities Research Reviews, 13, 136-142.

Kerkorian, D., McKay, M. \& Bannon, W. (2006). Seeking help a second time: Parents/caregivers' characterizations of previous experiences with mental health services for their children and perceptions of barriers to future use. American Journal of Orthopsychiatry, 76, 161-166.

Landmark, L. J., Ju, S., Zhang, D. (2010). Substantiated best practices in transition: Fifteen plus years later. Career Development for Exceptional Individuals, 33(3), 165-176.

Lynch, E. \& Hanson, M. (1998). Developing cross-cultural competence, (2 ${ }^{\text {nd }}$ ed.). York, PA: Maple Press Company.

Mack, K.G. (2008). Beyond the barriers: A qualitative investigation into the experiences of general pediatricians working with young children exhibiting developmental delays and disabilities. Graduate School Theses and Dissertations. Retrieved from http://scholarcommons.usf.edu/cgi/viewcontent.cgi?article=1371\&context=etd. 
Miles, M. B., \& Huberman, A. M. (1994). Qualitative data analysis: An expanded sourcebook ( $2^{\text {nd }}$ ed.). Thousand Oaks, CA: Sage.

Mount, N. \& Dillon, G. (2014). Parents' experiences of living with an adolescent diagnosed with an autism spectrum disorder. Educational \& Child Psychology, 31(4), 72-81.

Mulligan, B., John, M., Coombes, R., \& Singh, R. (2014). Developing outcome measures for a family intensive support service for children presenting with challenging behaviours. British Journal of Learning Disabilities, 43, 161-167.

Nachshen, J. S., Woodford, L. and Minnes, P. (2003). The family stress and coping interview for families of individuals with developmental disabilities: A lifespan perspective on family adjustment. Journal of Intellectual Disability Research, 47, 285-290.

Methodology for Niche K12 Rankings. (2017). Retrieved from https://www.niche.com/k12/rankings/methodology.

NC Innovations Waiver Services. (2017). Retrieved from https://www2.ncdhhs.gov/ncinnovations/.

Sutton, R. (2013). Students with disabilities: Making IDEA transition services work. Theses and Dissertations. Retrieved from http://rdw.rowan.edu/cgi/viewcontent.cgi?article=1459\&context=etd.

Webster, R. S. (2009). How evidence-based teaching practices are challenged by a Deweyan approach to education. Asia-Pacific Journal of Teacher Education, 37(2), 215-227. 
Weiss, J. \& Lunsky, Y. (2010). Service utilization in parents of youth and adults with intellectual disability who experience behavioral crisis. Journal of Mental Health Research in Intellectual Disabilities, 3, 145-163. 


\section{Appendix}

\section{Interview 1}

Adaptation to the Need for Help Questionnaire

(Douma, Dekker, and Koot, 2006)

1. Parent perception of problems:

-Describe any crises/major concerns has experienced in the last year:

-List diagnoses or serious problems and disruptive behaviors not diagnosed but contributed to crisis/major concerns:

(anger/temper, self-injurious, aggressive, property destruction, threats of suicide/self-harm/harm to others, anxiety)

2. Need for support:

-to what extent did you need support in the past year because of, or related to, the crisis/major concerns?:

1 - No Need 2 -Some Need 3 - Reasonably Strong Need 4 - Very Strong Need

A - A friendly ear for the parents to talk to

$\mathrm{B}$ - Information

C - Activities for the child

D - Respite Care

E- Financial Help

F - Child's Mental Health Care (Psychopharmacology or Therapy)

$\mathrm{G}$ - Parent Counseling 
3. Met need and effectiveness of support:

-if support was needed, was it received, and to what extent were you satisfied?:

1 - Not at All 2 -Somewhat (but not enough to help with the crisis) 3 - Very Helpful

A - A friendly ear for the parents to talk to - Received/Not Received

B - Information - Received/Not Received

C - Activities for the child - Received/Not Received

D - Respite Care - Received/Not Received

E - Financial Help - Received/Not Received

F - Child's Mental Health Care (Psychopharmacology or Therapy) - Received/Not Received $\mathrm{G}$ - Parent Counseling - Received/Not Received

4. Barriers to support:

-Negative experiences with professional help

-Not knowing where to find help

-Distance to get help

-Having difficulty describing the problem

-Steps to seek help were overwhelming

-Considered problem temporary

-No trust in professional help

-Fear of being a burden

-Wanted to handle the problem themselves

-Believed the problem was not serious

-Fears of labels/stigma

-Busy/Other Priorities

-Other people did not want you to seek help

5. Sharing of story: 


\section{Interview 2}

Adapted from the Family Stress and Coping Interview (FSCI)

(Nachshen, Woodford, \& Minnes, 2003)

Interviewer Instructions: Read the italicized statement below and then each "stressor" statement as listed and mark the stress ratings given by the parent or guardian. Where blanks appear, use the name of the child.

Instruction for Interviewee:

For the next questions, you will need the scale that we will go over in a moment. I am going to list some issues that you may or may not have encountered in your experiences as a parent of a child with special needs. You may have dealt with some of these issues in the past, and some may be coming up in the future. I'm going to ask you to rate a series of issues in terms of how stressful they are to you on a scale of 0 to 3. It is important that you tell me how stressful these issues are now, at this time in your life.

Please use the scale to help you decide on a rating. You can choose not to answer specific questions if it makes you uncomfortable. Also, if you find the issues too upsetting, or if you feel that you cannot complete the interview and wish to stop, we will do so, and can set up another time.

Not Stressful - 0 Mildly Stressful - 1 Moderately Stressful - 2 Extremely Stressful - 3

1. The diagnosis of as having a disability.

2. Explaining to others about_____'s disability.

3. Your feelings about the cause of ___ 's disability.

4. Dealing with friends/family/people in the neighborhood on a day-to-day basis.

5. Dealing with doctors and other allied health professionals.

6. Dealing with legal professionals.

7. Dealing with___ 's teachers and the educational/school system.

8. Creating and/or finding opportunities for to make friends and participate in activities.

9. Deciding on the best level of integration for

10. Making the decision concerning accommodations in the home or in the community.

11. Meeting the needs of your (other) children.

12. Meeting your own personal needs. 
13. Meeting the needs of your spouse/partner.

14. Maintaining satisfying friendships.

15. Dealing with 's sexuality.

17. Long-term planning for

19. Planning for emotional and social support for

20. Transportation.

21. Day to day assistance with care of

22. Time apart from

23. Dealing with financial and insurance issues.

24. Getting objective feedback about how I'm handling things related to 's disability.

25. Asking for information or advice related to 's disability. 
Transfer of Key Responses to Table

\begin{tabular}{|c|c|c|c|c|}
\hline $\begin{array}{l}\text { Q1-Parent perception } \\
\text { of problems }\end{array}$ & $\begin{array}{l}\text { Q2-Need for } \\
\text { supports }\end{array}$ & $\begin{array}{l}\text { Q3-Met need } \\
\text { and } \\
\text { effectiveness } \\
\text { of support }\end{array}$ & $\begin{array}{l}\text { Q4-Barriers } \\
\text { met }\end{array}$ & Q5-Story \\
\hline $\begin{array}{l}\text { List crises and major } \\
\text { concerns (diagnoses, } \\
\text { behaviors) }\end{array}$ & $\begin{array}{l}\text { List supports } \\
\text { needed (listener, } \\
\text { information, } \\
\text { child activities, } \\
\text { care, financial, } \\
\text { counseling) and } \\
\text { the extent of } \\
\text { need for each }\end{array}$ & $\begin{array}{l}\text { Was support } \\
\text { received? } \\
\text { How satisfied? }\end{array}$ & $\begin{array}{l}\text { List different } \\
\text { barriers }\end{array}$ & $\begin{array}{l}\text { Highlight story } \\
\text { transcript with } \\
\text { different colors to } \\
\text { identify (RQ1) need } \\
\text { for support, (RQ2) } \\
\text { barriers met, and } \\
\text { (RQ3) effectiveness } \\
\text { of supports. }\end{array}$ \\
\hline \multicolumn{5}{|c|}{ Sean } \\
\hline $\begin{array}{l}\text {-At age three, he was not } \\
\text { talking and only } \\
\text { repeating; Doctors } \\
\text { continued to dismiss } \\
\text { concerns and said him } \\
\text { being with his same age } \\
\text { peers in preschool, the } \\
\text { problem of not } \\
\text { talking/repeating would } \\
\text { go away } \\
\text {-Diagnosed with a } \\
\text { speech disorder at three, } \\
\text { but no mention of any } \\
\text { other developmental } \\
\text { disorder } \\
\text {-Diagnosed (with } \\
\text { Pervasive Development } \\
\text { Disorder-PDD) at age } \\
\text { five - identifiable on the } \\
\text { Autism Spectrum, but } \\
\text { not given confirmed } \\
\text { Autism diagnosis until } \\
\text { age nine } \\
\text {-Difficulty receiving } \\
\text { appropriate school } \\
\text { services - went six } \\
\text { months not in school } \\
\text { due to lack of } \\
\text { services/being accepted } \\
\text { into program } \\
\text {-No } \\
\text { integration/inclusion }\end{array}$ & $\begin{array}{l}\text {-Very strong } \\
\text { need for: } \\
\text {-A friendly } \\
\text { ear } \\
\text { to talk to } \\
\text {-Information } \\
\text {-Activities } \\
\text { for } \\
\text { their son } \\
\text {-Respite } \\
\text { Care } \\
\text {-Financial } \\
\text { Help } \\
\text {-Child's } \\
\text { Mental Health } \\
\text { Care }\end{array}$ & $\begin{array}{l}\text {-A friendly ear } \\
\text { to talk to - } \\
\text { Received } \\
\text {-Information - } \\
\text { Received } \\
\text {-Activities for } \\
\text { their son - } \\
\text { Received } \\
\text {-Respite Care - } \\
\text { Received } \\
\text {-Financial Help } \\
- \\
\underline{\text { Received }} \\
\text {-Child's Mental } \\
\text { Health Care - } \\
\underline{\text { Received }} \\
\text {-Parent } \\
\text { Counseling - } \\
\underline{\text { NOT Received }}\end{array}$ & $\begin{array}{l}\text {-Negative } \\
\text { experiences } \\
\text { with } \\
\text { professional } \\
\text { help: wait time } \\
\text { for } \\
\text { appointments } \\
\text {-Not knowing } \\
\text { where to find } \\
\text { help: no help } \\
\text { provided } \\
\text {-Steps to seek } \\
\text { help were } \\
\text { overwhelming: } \\
\text { no services, no } \\
\text { funding, } \\
\text { waiting } \\
\text { period(s) } \\
\text {-Considered } \\
\text { problem } \\
\text { temporary: } \\
\text { somewhat in } \\
\text { the beginning } \\
\text {-Fear of being } \\
\text { a burden: } \\
\text { didn't want to } \\
\text { beg } \\
\text {-Wanted to } \\
\text { handle the } \\
\text { problem } \\
\text { themselves: } \\
\text { mainly because }\end{array}$ & $\begin{array}{l}\text {-Emotional } \\
\text {-Tough } \\
\text {-Draining } \\
\text {-Frustrating } \\
\text {-Personal } \\
\text {-Nervous } \\
\text {-Want a clear } \\
\text { understanding } \\
\text {-Tried everything } \\
\text {-No answers } \\
\text {-Waiting game } \\
\text {-Unsure } \\
\text {-No knowledge } \\
\text {-Difficult } \\
\text {-Not getting } \\
\text { anywhere } \\
\text {-No support } \\
\text {-Unsure } \\
\text {-No options } \\
\text {-Police } \\
\text {-Guardianship } \\
\text {-No friendships } \\
\text {-Services } \\
\text {-Thankful }\end{array}$ \\
\hline
\end{tabular}


opportunities for him throughout the years

-At sixteen years old, he became more violent and physical, especially towards mom and sister (hitting, kicking, punching, biting, and cursing)

-At eighteen years old he was awarded access to home and community services through Medicaid

-Diagnoses: Autism, ADHD, Explosive Intermittent Disorder, Intellectual Disability Moderate

-Parents interested in a brain scan and genetics testing there was no

help

-Believed the problem was not serious: initially, because he could talk -Fears of labels/stigma: just wanted an answer

-Busy/other priorities: daughter has lived in a bubble

-Other people did not want to seek help: nonissue due to lack of education

\section{$\underline{\text { Chris }}$}

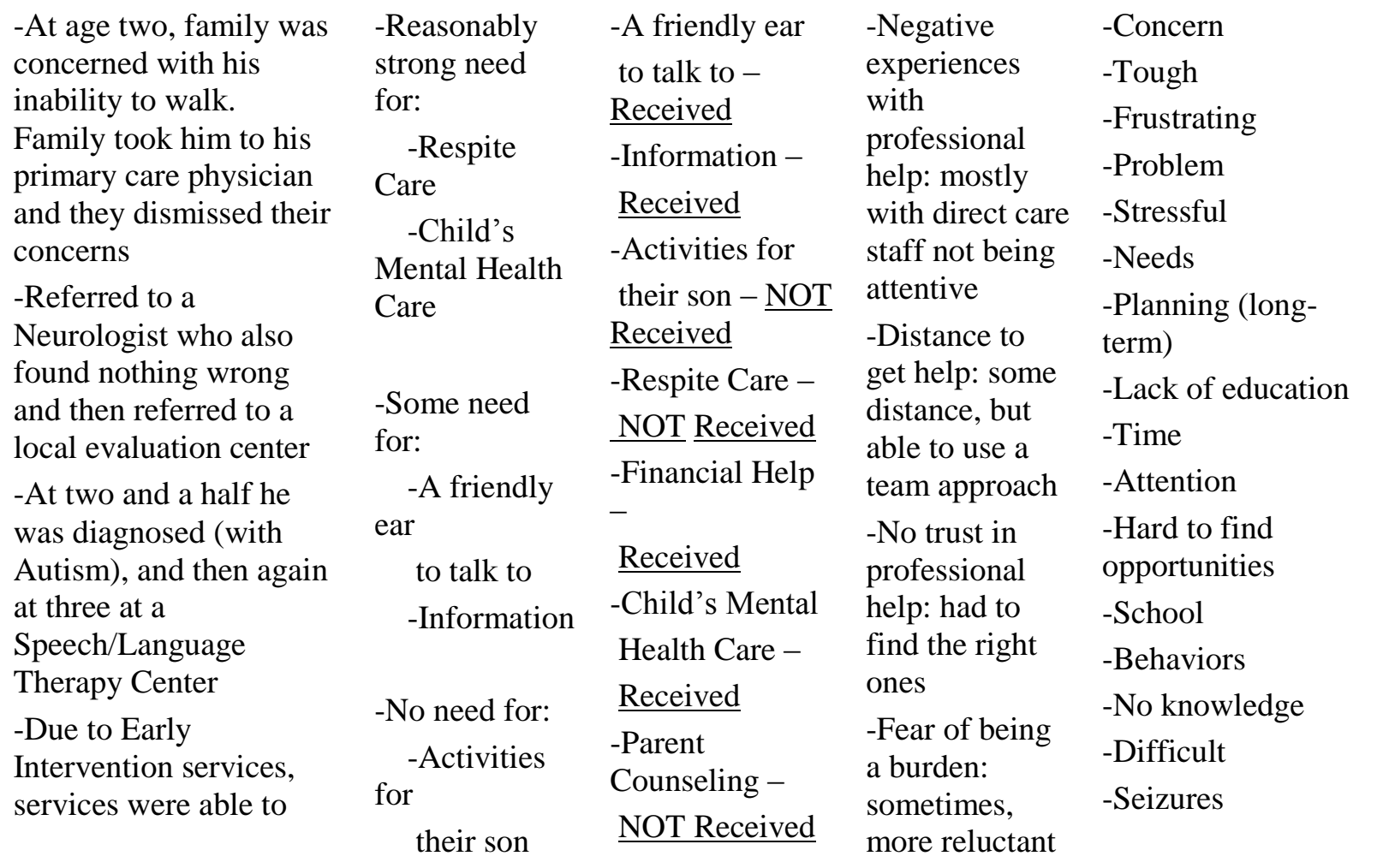


connect quickly with each other

-At four years old, family was able to acquire additional home and community services through CAP by asking questions of how other individuals in same evaluation center were receiving more "time" and wanting to learn as much as possible -Services have been in place for seventeen years

-Recent diagnosis of seizures is of gravest concern due to seriousness of occurrence(s) (i.e. not breathing, needing to call 911 on a regular basis, trial and error of medications to help manage)

-Diagnoses: Autism, ADHD, Explosive Intermittent Disorder, Intellectual Disability Moderate

-Family is interested in possible Respite opportunities/availability

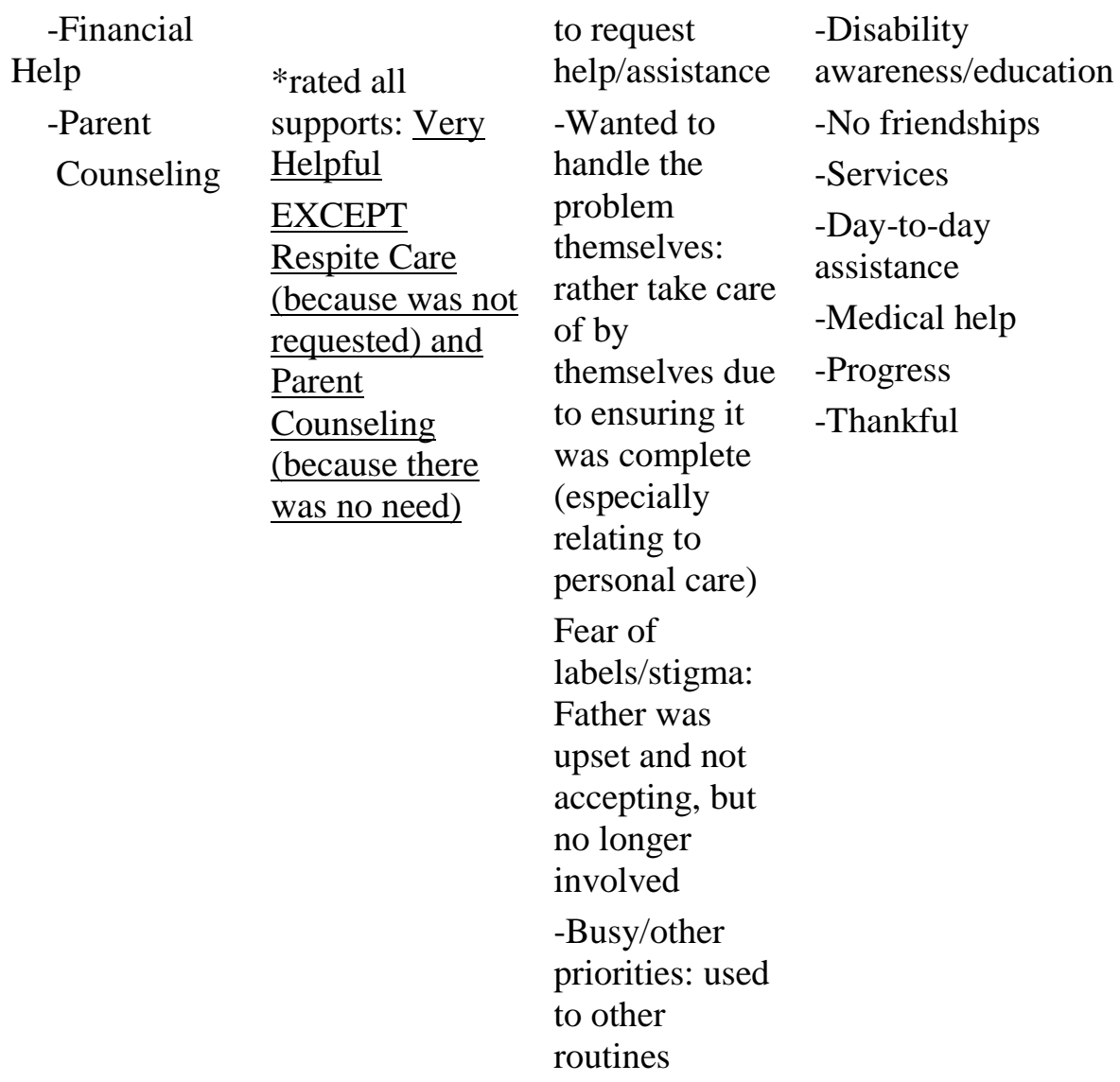

